\title{
Priorización, Limpieza Viral, Producción de Semilla de Calidad Básica y Devolución de Cultivares Nativos Libres de Virus
}

\author{
Víctor Iriarte, Ana G. Badani, Carmen L Villarroel, Gino Aguirre, \\ Enrique N. Fernández-Northcote ${ }^{1}$
}

\section{Resumen}

Ocho instituciones colaboradoras (AGRUCO, CENDA, CPA, ACRA, PIABS, CESA, UTO, COPLA), y las comunidades a las que apoyan, han seleccionado en zonas con características extremas, cultivares de papa nativa cultivados la mayoría en alturas superiores a los 3,500 $\mathrm{m}$. De ellos 24 fueron priorizados con PROINPA para su limpieza viral, en base a sus características sobresalientes de alta rusticidad frente a factores abióticos y por su importancia social en la elaboración de chuño (tubérculo deshidratado negro), tunta (tubérculo deshidratado blanco), waicu (tubérculo cocido con cáscara), y cocido en fresco. Con el uso de anticuerpos apropiados para la detección de variantes andinas de los virus comunes de la papa en DAS-ELISA, se ha limpiado de virus los 24 cultivares de papa nativa, de los cuales se ha producido semilla de calidad básica en la E.E. Toralapa y en condiciones in situ en camas protegidas construidas con materiales rústicos del lugar. Asimismo a la fecha se han producido tubérculossemillas de alta calidad en parcelas semillaras de los mismos agricultores. Los cultivares nativos de papa, limpios, han sido devueltos a sus centros de recolección a través de los sindicatos de agricultores e instituciones involucradas. Se ha realizado la comparación preliminar de semilla libre de virus con la semilla proveniente de selección positiva y semilla del agricultor, con resultados muy satisfactorios. Se realizaron eventos de capacitación a 282 agricultores para el manejo de los cultivares libres de virus. La demanda al presente por los cultivares nativos limpios contribuirá al mantenimiento de la biodiversidad y apoyará a una agricultura más sostenible.

\footnotetext{
${ }^{1}$ Programa de Investigación de la Papa PROINPA (IBTA-CIP-COSUDE). Al presente Fundación PROINPA. Casilla 4285, Cochabamba, Bolivia. Correo electrónico: e.fernandez@cgiar.org.
} 
Palabras claves adicionales: Degeneración, virus, PVY, PLRV, PTV-p $(P V V)$.

\title{
Prioritization, Virus Clean-Up, Basic Quality Seed Production, and Refurn fo Formen of Virus- Free Native Cultivars
}

\begin{abstract}
Summary
Eight collaborating institutions (AGRUCO, CENDA, CPA, ACRA, PIABS, CESA, UTO, COPLA) and the communities that these institutions support, selected potato native cultivars grown $3,500 \mathrm{~m}$. Twenty-four of them were prioritized with IPA for virus clean up. These cultivars have excellent characteristics like rusticity against abiotic factors, and social importance for factors such as the preparation of "chuño" (black rated potato), "tunta" (white dehydrated potato), "waicu" (potato cooked with its peel), and cooked fresh. Basic seed have been produced from the 24 native cultivars in the oralapa Experimental Station or in situ in protected rustic beds. High quality seed tubers have also been produced in farmers' plots. The virus-free native cultivars have been returned to the original communities where the cultivars were collected. From preliminary tests, the yield from the virus-free seed tubers is very satisfactory, with regards to the farmers' seed tubers or to those from positive selection. The demand for the virus-free native cultivars will contribute to maintaining biodiversity and will contribute to a sustainable agriculture.
\end{abstract}

Additional index words: Degeneration, virus, PVY, PLRV, PTV-p (PVV).

\section{Introducción}

La papa es un cultivo básico y de seguridad alimentaria para la población boliviana. Para más de 200,000 familias de pequeños agricultores que constituyen entre el 30 y $40 \%$ del total de campesinos del país (Zeballos, 1997), la papa constituye la principal de alimento e ingresos. El consumo per capita entre 100 a 120 
kg/año (Zeballos, 1997) es uno de los más altos en el mundo. Cerca de 130,000 ha son dedicadas a su cultivo con un rendimiento promedio en los Andes Bolivianos de $5 \mathrm{t} / \mathrm{ha}$, mientras que el mundial es de 14 t/ha y de 26 t/ha en los países desarrollados (Horton, 1992) (Zeballos, 1997). La papa, es el cultivo más importante en la economía agrícola del país (Bojanic, 1995). Sin embargo, los rendimientos son bajos debido a diversos factores limitantes siendo uno de los más importantes, la mala calidad de la semilla debido a su degeneración.

La utilización de tubérculos-semillas provenientes de plantas infectadas con virus en sucesivas campañas de siembra producen menos tubérculos o estos son más pequeños que los de las plantas sanas. Ello conduce a la degeneración del cultivar con pérdidas en los rendimientos superiores al $80 \%$. El agricultor bajo estas condiciones no desea utilizar tubérculos-semillas de su propia cosecha (semilla "cansada") y busca una fuente de semilla limpia, si ésta no está disponible los cultivares nativos degenerados son descartados por los agricultores y reemplazados por otros cultivares o cultivos, perdiéndose la diversidad genética nativa.

Se estima que al presente se cultivan en el país alrededor de 1,500 cultivares nativos, una muestra de alrededor de 700 de ellos se mantienen en el Banco Nacional de Germoplasma de Bolivia, en la Estación Experimental de Toralapa. Más del $50 \%$ de las plantas de estos cultivares han sido descartadas mediante una selección negativa por expresiones de virosis y degeneración (FernándezNorthcote,1992; M.L. Ugarte, comunicación personal) y al presente más del $80 \%$ de ellos muestran síntomas o infección por virus.

Debido al problema de la degeneración de los cultivares (semilla cansada), los agricultores constantemente demandan una semilla de mejor calidad de sus cultivares preferidos. Por lo tanto, a solicitud de ocho instituciones a nivel nacional: Agroecología Universidad Cochabamba (AGRUCO), Centro de Comunicación y Desarrollo Andino (CENDA), Central de Productores Agropecuarios (CPA), Asociación de Cooperación en África y América Latina (ACRA), Proyecto de Investigación Agraria Bautista Saavedra (PIABS), Centro de Servicios Agropecuarios (CESA), Universidad Técnica de Oruro (UTO), y Centro Orureño de Planificación (COPLA) y de las comunidades a las que apoyan, se seleccionaron diversos cultivares nativos de los cuales 24 fueron priorizados con PROINPA para su limpieza viral, en base a sus características sobresalientes de alta 
rusticidad frente a factores abióticos y por su importancia social en la elaboración de chuño (tubérculo deshidratado negro), tunta (tubérculo deshidratado blanco), waiku (tubérculos cocidos con cáscara) y cocido en fresco. En el presente trabajo, se reporta su limpieza viral, producción de semilla básica que luego era devuelta a las comunidades de origen así como entregada a otras interesadas.

Avances del presente trabajo han sido previamente reportados (Badani et al., 1996, Iriarte et al. 1996, Iriarte et al., 1998)

\section{Materiales y Métodos}

\section{Priorización y recolección}

Se priorizaron cultivares nativos de los Departamentos de Cochabamba, La Paz, Oruro y Tarija (Figura 1). Luego se procedió a la recolección de seis tubérculos por cultivar, procedentes de plantas de preferencia previamente marcadas por selección positiva, de acuerdo a los siguientes criterios: sanidad, buena constitución, vigor, desarrollo foliar, y características típicas del cultivar.

Los tubérculos colectados fueron sembrados en invernadero donde a los 30 días de la emergencia se realizó una detección de infección viral pre-termoterapia mediante la prueba de inmunoadsorción con conjugados enzimáticos, modalidad directa de emparedado de doble anticuerpo (DAS-ELISA), para los virus de papa, virus $X$ (PVX), virus Y (PVY), virus S (PVS), virus latente andino de la papa (APLV), virus del moteado andino de la papa (ApoMV), virus del enrrollamiento de las hojas (PLRV), y virus peruano del tomate-strain de papa (PVT-p) conocido también como virus $\mathrm{V}$ de la papa (PVV). Se utilizó además anticuerpos PVXY que detectan probablemente variantes diferentes de PVX y de PVY o PVT-p. Se utilizaron anticuerpos y conjugados producidos en el Centro Internacional de la Papa (CIP) y de BIOREBA.

Para la limpieza viral se seleccionó, por cultivar, la planta con menos problemas patológicos. Se procedió al corte y desinfección de esquejes, para su posterior establecimiento in vitro.

Previa micropropagación se sometieron a termoterapia $\left(37^{\circ} \mathrm{C} / 24 \mathrm{~h}\right.$, luz/cuatro semanas), plántulas in vitro de cada cultivar. Luego de la termoterapia con la ayuda de un microscopio-estereoscópico, se 
procedió a la escisión de 20 meristemas apicales por cultivar, los cuales fueron sembrados para su regeneración en un medio de cultivo que contenía sales de MS (Murashige \& Skoog, 1962), ácido giberélico (0.1 ppm), ácido nicotínico (0.5 ppm), kinetina (0.04 ppm), sacarosa (2.5\%), y agar (0.75\%), a pH 5.7. Luego de la regeneración se seleccionaron hasta seis clones de las plántulas más pequeñas, las cuales fueron aclimatadas, desarrolladas en invernadero (plantas madre) para su verificación sanitaria mediante ELISA y en el material negativo a virus por plantas indicadoras para los virus indicados anteriormente. Se hizo una segunda verificación sanitaria en las plantas provenientes de la primera generación de tubérculos de la planta madre.

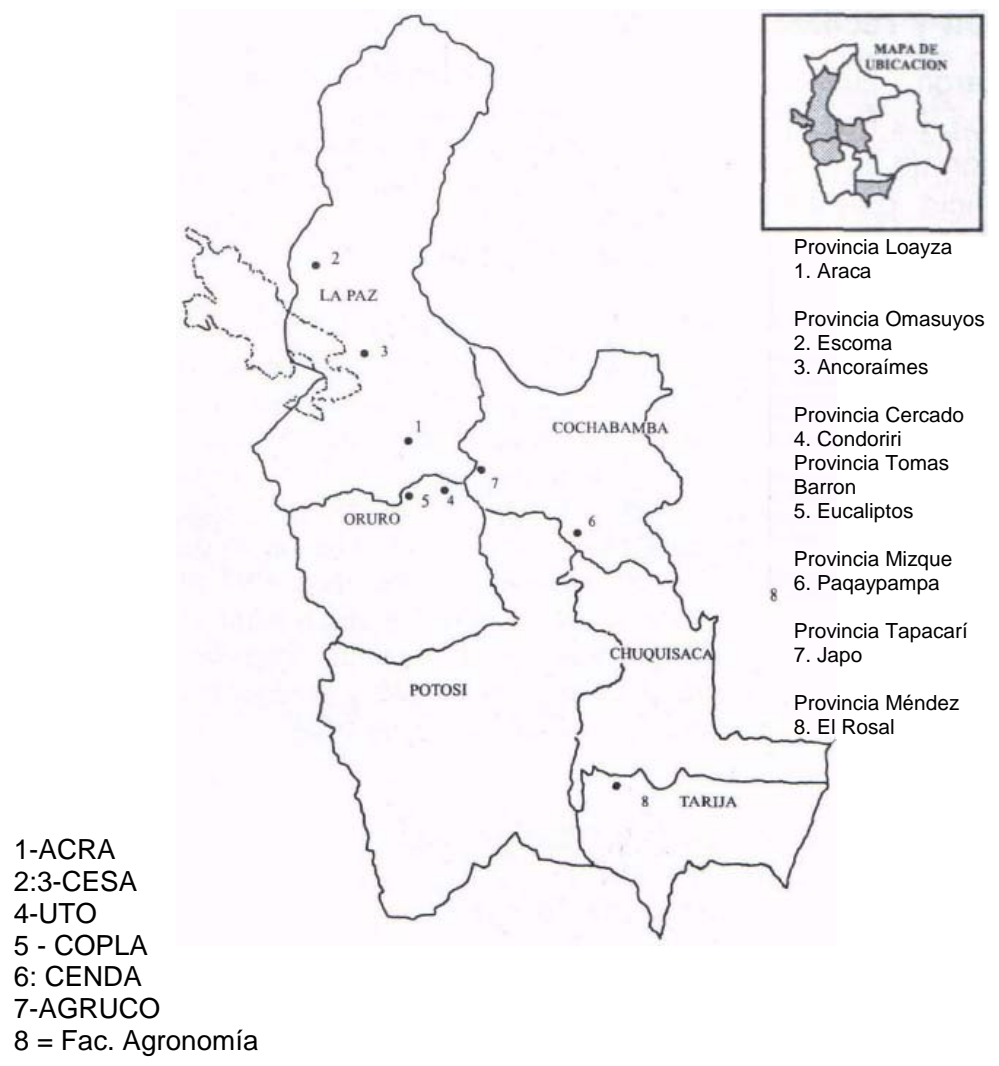

Figura 1. Ubicación de las localidades donde se cultiva y fueron colectados los 24 cultivares de papa nativa priorizados para su limpieza: Instituciones involucradas 
Una vez confirmada la sanidad de las plantas, en laboratorio se procedió a la multiplicación in vitro de un clon limpio (clon libre de patógenos de acuerdo a las pruebas de detección realizadas) por cultivar mantenido in vitro. Paralelamente otros dos clones limpios incluyendo el clon en multiplicación se mantuvieron in vitro en conservación $\left(8^{\circ} \mathrm{C}\right.$, con retardantes de crecimiento).

Plántulas in vitro de cada cultivar limpio fueron aclimatadas en el invernadero de la E.E. Toralapa para la producción de semilla prebásica o el futuro trasplante a camas protegidas para la producción de semilla básica. Con la semilla prebásica se produjo también semilla básica en camas protegidas. La semilla básica fue producida ex situ en la E.E. Toralapa e in situ en varias de las comunidades de origen de los cultivares nativos. Posteriormente se comparó en parcelas semilleras tres calidades de semilla: semilla libre de virus, semilla proveniente de selección positiva y semilla del agricultor.

La devolución de la semilla prebásica o básica a sus localidades de origen se realizó en coordinación con el sindicato de agricultores y las instituciones involucradas.

Se identificaron zonas para la construcción de camas protegidas de $15 \mathrm{~m}^{2}$ (10 m largo $\times 1.5 \mathrm{~m}$ de ancho). Se tomó en cuenta la disponibilidad de agua, de material en el lugar para la construcción de la cama protegida, y cercanía a la casa del agricultor. Asimismo se tomó en consideración la orientación del sol y la pendiente del terreno (Aguilera 1995.)

Paralelamente a la devolución se capacitó agricultores y técnicos en la construcción, siembra y manejo de camas protegidas, pestes y enfermedades priorizadas en la zona, cosecha, almacenamiento, selección positiva y multiplicación rápida a partir de brotes (Canaviri, 1995.)

La evaluación del impacto del material devuelto se realizó a través de un monitoreo del manejo de la producción de semilla, verificando la sanidad, organizando su futura distribución, y realizando la caracterización in situ de los cultivares limpios. 


\section{Resultados}

\section{Priorización}

Se priorizaron y limpiaron 24 cultivares nativos (Tabla 1). La diversidad de nombres en los cultivares nativos selecciona dificultaron la adecuada identificación de los cultivares priorizados que de una comunidad a otra podría haber cambiado de nombre. Por esta razón se realizaron análisis morfológicos y pruebas electroforesis con la colaboración de la Ing. M.L. Ugarte (Dpto. Recursos Genéticos, PROINPA), para determinar la similitud o diferencia de los cultivares. Además se consideró la apreciación de técnicos y agricultores.

\section{Limpieza viral}

Los virus más comunes detectados en las pruebas serológicas termoterapia fueron: PVX, PVA (muy posiblemente no PVA variantes andinas de PVY o PTV-p) utilizando anticuerpos BIOREBA, y PTV-p (PVV) (Tablas 2, 3).

Se logró la limpieza viral de los 24 cultivares nativos priorizados (Tabla 1 y Figura 2).

Durante el proceso de limpieza se presentaron contaminaciones bacterianas las cuales fueron controladas agregando Rifampicina (30 ppm) al medio de cultivo, después de su autoclaveado.

En la fase de termoterapia pocos fueron los cultivares que soportaron los $37^{\circ} \mathrm{C} / 4$ semanas, esto dificultó su manejo implantación del meristema en el medio de cultivo, donde algún estos meristemas llegaron a deshidratarse. La mayoría de meristemas regeneraron en un tiempo de dos a tres meses embargo, los meristemas regeneraron mucho más rápido cuando fueron sometidos a luz natural. 
Tabla 1. Instituciones colaboradoras, comunidades solicitantes, y cultivares nativos de papa priorizados libres de virus

\begin{tabular}{|c|c|c|c|c|c|}
\hline Cultivar & Especie & Colaboradores & Provincia & $\begin{array}{c}\text { Zona o } \\
\text { Comunidad }\end{array}$ & $\begin{array}{c}\text { Altitud } \\
\text { (msnm) }\end{array}$ \\
\hline Milagro & S. stenotomum & ACRA (La Paz) & Loayza & Collana & 4100 \\
\hline Pali Rojo & $\begin{array}{l}\text { S. tuberosum } \\
\text { ssp. andigena }\end{array}$ & ACRA (La Paz) & Loayza & Collana & 4100 \\
\hline Pali Negra & $\begin{array}{l}\text { S. tuberosum } \\
\text { ssp. andigena }\end{array}$ & ACRA (La Paz) & Loayza & Collana & 4100 \\
\hline Sani Negra & $\begin{array}{l}\text { S. tuberosum } \\
\text { ssp. andigena }\end{array}$ & ACRA (La Paz) & Loayza & Collana & 4100 \\
\hline Bola Luk'i & S. curtilobum & AGRUCO (Cbba.) & Tapacarí & Japo & 4200 \\
\hline Chojlla Luk'i & S. juzepczukii & AGRUCO (Cbba.) & Tapacarí & Japo & 4200 \\
\hline Khuchi Sullu & S. stenotomun & AGRUCO (Cbba.) & Tapacarí & Japo & 4200 \\
\hline Majarillo & $\begin{array}{l}\text { S. tuberosum } \\
\text { ssp. andigena }\end{array}$ & AGRUCO (Cbba.) & Tapacarí & Japo & 4200 \\
\hline Peraza Luk'i & S. juzepczukii & AGRUCO (Cbba.) & Tapacarí & Japo & 4200 \\
\hline Q'ala Ajanhuiri & S. ajanhuiri & AGRUCO (Cbba.) & Tapacarí & Japo & 4200 \\
\hline Qetu Luk'i & S. juzepczukii & AGRUCO (Cbba.) & Tapacarí & Challa Grande & 3850 \\
\hline Moroq'o Luk'i & S. juzepczukii & AGRUCO (Cbba.) & Tapacarí & Challa Grande & 3900 \\
\hline Laqmu & $\begin{array}{l}\text { S. tuberosum } \\
\text { ssp. andigena }\end{array}$ & CENDA (Cbba.) & Mizque & Rumimuku & 2900 \\
\hline Puka Ñawi & $\begin{array}{l}\text { S. tuberosum } \\
\text { ssp. andigena }\end{array}$ & CENDA (Cbba.) & Mizque & Rumimuku & 2900 \\
\hline Isla & $\begin{array}{l}\text { S. tuberosum } \\
\text { ssp. andigena }\end{array}$ & CESA (La Paz) & Omasuyos & Macamaca & 3900 \\
\hline Wila Imilla & $\begin{array}{l}\text { S. tuberosum } \\
\text { ssp. andigena }\end{array}$ & $\begin{array}{l}\text { CESA (La Paz) } \\
\text { Central de Prod. }\end{array}$ & Omasuyos & Macamaca & 3900 \\
\hline Yacu Imilla & $\begin{array}{l}\text { S. tuberosum } \\
\text { ssp. andigena }\end{array}$ & $\begin{array}{l}\text { Agropecuarios } \\
\quad(\text { La Paz) }\end{array}$ & Loayza & Cochira & 2900 \\
\hline Runa Amarga & S. juzepczukii & COPLA (Oruro) & Tomás Barrón & Chapicollo & 3765 \\
\hline Sakampaya & $\begin{array}{l}\text { S. tuberosum } \\
\text { ssp. andigena }\end{array}$ & COPLA (Oruro) & Tomás Barrón & Chapicollo & 3765 \\
\hline Collareja Larga & $\begin{array}{l}\text { S. tuberosum } \\
\text { ssp. andigena }\end{array}$ & PROINPA(Tarija) & Méndez & Papachacra & 3450 \\
\hline Mayu Rumi & $\begin{array}{l}\text { S. tuberosum } \\
\text { ssp. andigena }\end{array}$ & PIABS (La Paz) & B. Saavedra & Chullina & 3900 \\
\hline Yurak Luk'i & S. curtilobum & PIABS (La Paz) & B. Saavedra & Chullina & 3900 \\
\hline $\begin{array}{c}\text { Luk'i Moroq'o } \\
\text { Blanco }\end{array}$ & S. juzepczukii & UTO (Oruro) & Cercado & Condoriri & 3830 \\
\hline Pali Morado & $\begin{array}{l}\text { S S. tuberosum } \\
\text { ssp. andigena }\end{array}$ & UTO (Oruro) & Cercado & Condoriri & 3830 \\
\hline
\end{tabular}




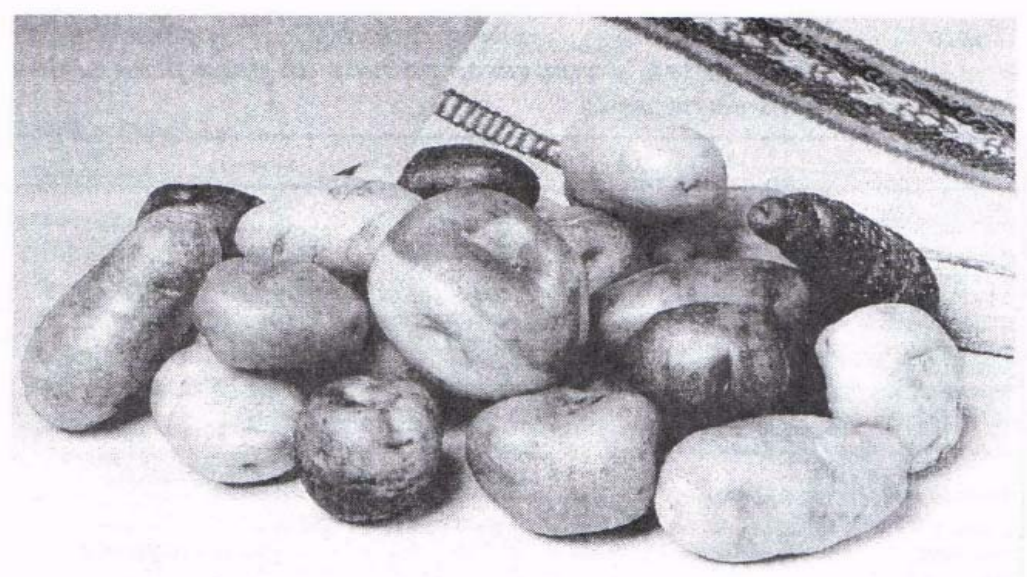

Figura 2. Muestra de tubérculos de cultivares nativos luego del proceso de limpieza viral.

Tabla 2. Análisis serológico (DAS-ELISA) pre-termoterapia de cultivares priorizados en 1992-93.

\begin{tabular}{|l|cccccccc|}
\hline \multirow{1}{*}{\multicolumn{1}{|c|}{ Cultivar }} & \multicolumn{7}{|c|}{ Virus detectados } \\
\cline { 2 - 9 } & PVX & PVXY* & PVY & PVA $^{* *}$ & PVS & PLRV & APLV & ApoMV \\
\hline Moroq'o Luk'i & + & + & - & - & - & - & - & - \\
Qetu Luk'i & + & + & - & - & - & - & - & - \\
Chojlla Luk'i & + & + & - & - & - & - & - & - \\
Majarillo & + & + & - & - & - & - & - & - \\
Puka Nawi & - & - & - & - & - & - & - & - \\
Q'ala Ajanhuiri & - & - & - & - & - & - & + & - \\
Peraza Luk'i & - & + & - & - & - & - & - & - \\
Khuchi Sullu & - & + & - & - & - & - & - & - \\
Bola Luk'i & - & - & - & - & - & - & - & - \\
$\%$ mu e str a & 44 & 66 & 0 & 0 & 0 & 0 & 11 & 0 \\
positivas & & &
\end{tabular}

* No se hizo DAS-ELISA para PTV-p (PVV).

** Los anticuerpos en PVXY (CIP) y PVA (BIOREBA), detectan probablemente variantes andinas diferentes de PVX o PVY, y de PVY o PTV$p$ y no de PVA respectivamente 
Tabla 3. Porcentaje de virus detectados en 15 cultivares de papa nativa priorizados en la gestión 1994-95.

\begin{tabular}{|lcrrrrrrrrr|}
\hline \multicolumn{10}{|c|}{ Porcentaje de virus detectados pre-termoterapia } \\
\hline Cultivares & PVX & PVXY* $^{*}$ & PVY & PVA $^{*}$ & PTV-p & PVS & PLRV & APLV & ApoMV \\
\hline Papa nativa & 7 & 40 & 13 & 47 & 33 & 27 & 0 & 7 & 13 \\
\hline
\end{tabular}

* Los anticuerpos en PVXY (CIP) y PVA (BIOREBA), detectan probablemente variantes andinas diferentes de PVX o PVY, y de PVY o PTV-p y no de PVA, respectivamente.

En dos de los cultivares, Bola Luk'i, y Puka Ñawi, no se detectó virus Tabla 2). Sin embargo, estos cultivares en la zona de recolección presentan síntomas de virosis. Es probable que las plantas pretermoterapia utilizadas en DAS-ELISA, hayan estado infectadas con PTV-p (PVV) u otras variantes de virus no detectados con los reactivos utilizados en la fase de pre-termoterapia. Luego del proceso de limpieza viral estos dos cultivares así como los otros 22, no mostraron síntomas de virosis, ni se ha detectado virus en las DASELISA e inoculación en plantas indicadoras realizadas.

El método utilizado para la limpieza viral (termoterapia en plántulas y escisión de meristemas), ha tenido un 98\% de eficiencia, es decir que en la mayoría de las plantas regeneradas de meristemas, al pasar por la verificiación sanitaria en las dos etapas, no se detectó la presencia de virus.

Las Instituciones colaboradoras, asumieron la responsabilidad de apoyar a las comunidades interesadas en la multiplicación y manejo apropiado de los cultivares limpios a fin de mantener su calidad y su difusión.

\section{Multiplicación y devolución a las zonas de origen de los cultivares nativos}

Luego de realizada la verificación sanitaria se procedió a la multiplicación de plántulas in vitro de nueve cultivares limpios (priorizados en 1992-1993) (Tabla 2) para la producción de semilla prebásica en el invernadero de la Estación Experimental de Toralapa. El total de semilla prebásica obtenida fue de $40 \mathrm{~kg}$ (4,708 tubérculos) (Tabla 4). 
Tabla 4. Rendimiento total en tamaño, número y peso de tubérculossemilla de nueve cultivares nativos (Campaña 94-95). Invernadero E.E. Tora lapa.

\begin{tabular}{|l|cccc|c|c|}
\hline \multicolumn{1}{|c|}{ Cultivar } & \multicolumn{4}{c|}{ Tamaños } & No. total & $\begin{array}{c}\text { Peso total } \\
(\mathrm{kg})\end{array}$ \\
\cline { 2 - 5 } & II & III & IV & V & & \\
\hline Bola Luk'i & 48 & 142 & 206 & 206 & 602 & 5.8 \\
Chojlla Luk'i & 115 & 163 & 131 & 131 & 409 & 2.7 \\
Q'ala Ahanhuiri & 20 & 129 & 105 & 135 & 389 & 4.4 \\
Qetu Luk'i & 135 & 340 & 251 & 251 & 690 & 4.7 \\
Khuchi Sullu & 38 & 77 & 153 & 148 & 416 & 2.4 \\
Majarillo & 260 & 370 & 210 & 210 & 840 & 5.6 \\
Moroq'o Luk'i & 111 & 345 & 500 & 500 & 956 & 5.2 \\
Peraza Luk'i & 15 & 230 & 225 & 225 & 470 & 4 \\
Puka Nawi & 50 & 104 & 123 & 61 & 336 & 5.2 \\
\hline Total & & & & 4708 & 40 \\
\hline
\end{tabular}

A fin de acelerar la entrega de semilla de calidad básica de los nueve cultivares limpios, éstos fueron multiplicados en camas protegidas, tanto en la Estación Experimental Toralapa (ex situ) como en sus centros de recolección (in situ) a partir de la semilla prebásica producida en el invernadero (Figura 3). Tres cultivares fueron plantados en camas protegidas, tanto en su comunidad de recolección (in situ) como en la E.E. Toralapa (ex situ). En el caso de los seis restantes, por disponibilidad de semilla, sólo se plantaron en camas protegidas de la E. E. Toralapa. Las observaciones sintomatológicas y los análisis serológicos (DAS-ELISA) realizados no indicaron infección por virus. 


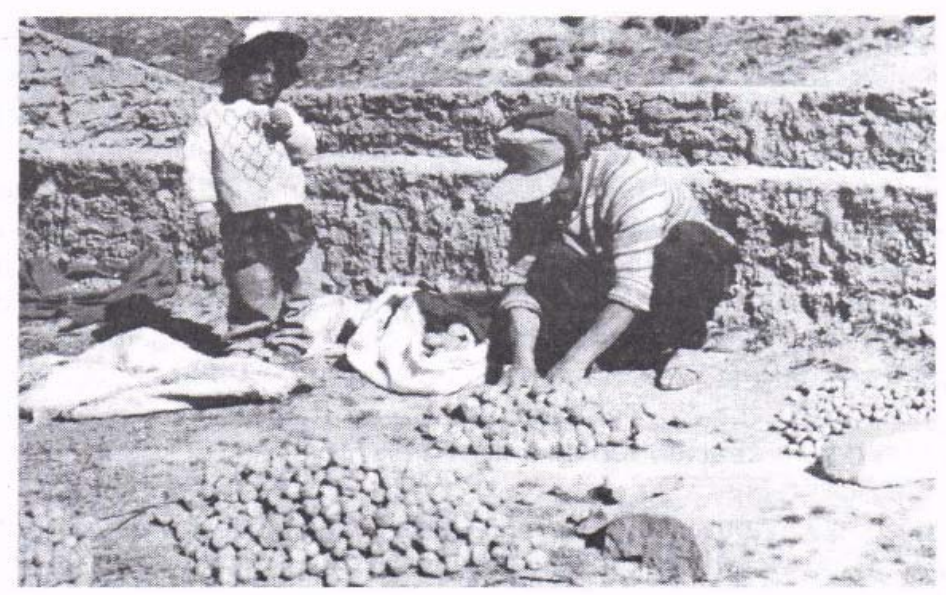

Figura 3. Producción de semilla de calidad básica de un cultivar nativo limpio en una cama protegida de la comunidad de Llallagua a partir de la semilla prebásica producida en el invernadero de la E.E. Toaralapa.

Se obtuvieron mejores rendimientos in situ debido probablemente a factores de adaptación de los cultivares y/o a un mejor sustrato (puruma, virgen) utilizado en las camas protegidas especialmente en Japo, con relación al de la E.E. Toralapa (Tabla 5).

Tabla 5. Rendimiento en camas protegidas de cultivares de papa nativa in situ y ex situ (1995-1996).

\begin{tabular}{|c|c|c|c|c|c|c|c|}
\hline \multirow{2}{*}{ Cultivares } & \multicolumn{4}{|c|}{ In situ } & \multicolumn{2}{c|}{ Ex situ } & \multirow{2}{*}{$\begin{array}{c}\text { Producción } \\
\text { total } \\
\text { (Kg.) }\end{array}$} \\
\cline { 2 - 7 } & \multicolumn{2}{|c|}{ Japo } & \multicolumn{2}{c|}{ Tapacarín } & \multicolumn{2}{c|}{ E.E. Toralapa } & \\
\cline { 2 - 6 } & Tub./pl & Kg./m & Tub./pl & Kg./m² & Tub./pl & Kg./m & \\
\hline Puka Ñawi & & & 10 & 4 & 12 & 4 & 113 \\
Majarillo & 14 & 5 & & & 6 & 3 & 125 \\
Qetu Luk'i & $15-18$ & 5 & & & 8 & 2 & 98 \\
Moroq'o Luk'i & $14-32$ & 9 & & & $6-8$ & 2 & 158 \\
Kala Ajanhuiri & & & & & $10-12$ & 2 & 30 \\
Kuchi Sullu & & & & & $10-12$ & 2 & 30 \\
Peraza Luk'i & & & & & $8-10$ & 2 & 30 \\
Bola Luk'i & & & & & $10-12$ & 3 & 45 \\
Chojlla Luk'i & & & & & 12 & 2 & 0 \\
\hline
\end{tabular}


En esta etapa, se realizaron eventos de capacitación a 282 agricultores de las comunidades de origen: 40 agricultores líderes de Raqaypampa Provincia Mizque, 62 agricultores en Japo Provincia Tapacari, 50 agricultores en Chullina Provincia Bautista Saavedra, 45 agricultores en Maca Maca, 42 agricultores en Chontamarca Provincia Omasuyos, 40 agricultores en Ayjadera Provincia Loayza y 45 agricultores en Eucaliptos Provincia Tomás Barrón, lo que contribuyó al buen manejo de los cultivares en las camas protegidas in situ e incentivó la construcción por ellos mismos de más camas protegidas para la próxima campaña, a fin de acelerar la difusión de los cultivares limpios. También estuvieron motivados e interesados para una multiplicación rápida a través de brotes.

La producción obtenida fue entregada a los agricultores de JapoTapacarí en coordinación con las instituciones que promovieron su limpieza. Se inició además con ellos un monitoreo de la semilla entregada. Esta fue manejada por familias mejoradoras de semilla de la comunidad y asociación de productores de semilla en un sistema rotativo, comprometiéndose a la devolución de un $50 \%$ más de le cantidad inicialmente entregada.

Luego la semilla de calidad básica se plantó en parcelas semilleras de agricultores, realizando una comparación con la semilla de agricultor proveniente de selección positiva y semilla del agricultor si selección positiva.

Plántulas in vitro de los 15 cultivares priorizados en 1994-195 además de los nueve priorizados en 1992-1993 fueron trasplantadas a camas protegidas in situ o ex situ, a razón de 234 plántulas p cultivar a fin de acelerar su devolución; de esta manera se redujo u campaña en la devolución de semilla de calidad básica a sus centros de origen.

Para el trasplante in situ las plántulas fueron transportadas en sus magentas de desarrollo tomando la precaución de que el medio de cultivo esté un poco endurecido (en proceso de secamiento). El transporte tomó entre dos a tres días. In situ las plántulas fue aclimatadas en las camas protegidas construidas por los mismos agricultores. El prendimiento estuvo entre el 90 al $100 \%$. Los rendimientos fueron mejores in situ dependiendo del cultivar nativo (Tabla 6).

Tabla 6. Rendimiento (Kg.) de 24 cultivares de papa nativa en camas protegidas $\left(15 \mathrm{~m}^{2}\right)$ in situ y ex situ, a partir de plántulas in vitro. 


\begin{tabular}{|c|c|c|c|c|c|c|c|c|}
\hline \multirow{2}{*}{ Cultivar } & \multicolumn{6}{|c|}{ In situ } & \multirow{2}{*}{\begin{tabular}{|l|} 
Ex situ \\
E.Toralapa
\end{tabular}} & \multirow{2}{*}{\begin{tabular}{|c} 
Prod. \\
total \\
$\mathrm{Kg}$.
\end{tabular}} \\
\hline & Tapacarí & Mizque & Loayza & Omasuyos & B. Saavedra & Cercado & & \\
\hline Pukañawi & & 18 & & & & & 12 & 30 \\
\hline Majarillo & 38 & & & & & & 14 & 52 \\
\hline Q'etu Luk'i & 7 & & & & & & 18 & 25 \\
\hline Morok'o Luk'i & 10 & & & & & & 21 & 31 \\
\hline $\begin{array}{l}\text { Q'ala } \\
\text { Ajanhuiri }\end{array}$ & 21 & & & & & & 17 & 38 \\
\hline Kuchi Sullu & 12 & & & & & & 22 & 34 \\
\hline Peraza Luk'i & 5 & & & & & & 23 & 28 \\
\hline Bola Luk'i & 37 & & & & & & 31 & 68 \\
\hline Chojlla Lukí & 20 & & & & & & 19 & 39 \\
\hline Sani Negra & & & 29 & & & & 12 & 41 \\
\hline Pali Rojo & & & 29 & & & & 42 & 71 \\
\hline Pali Negra & & & 29 & & & & 22 & 51 \\
\hline Milagro & & & 59 & & & & 46 & 105 \\
\hline Wila Imilla & & & & & & & 55 & 55 \\
\hline Isla & & & & 28 & & & 32 & 60 \\
\hline Yurak Luk'i & & & & & 25 & & 25 & 50 \\
\hline Mayu Rumi & & & & & & & En proceso & \\
\hline Yaku Imilla & & & & & & & 38 & 38 \\
\hline $\begin{array}{l}\text { Luk'i Moroq'o } \\
\text { B. }\end{array}$ & & & & & & 39 & 24 & 63 \\
\hline $\begin{array}{l}\text { Runa } \\
\text { Amarga }\end{array}$ & & & & & & 48 & 33 & 81 \\
\hline Sakampaya & & & & & & & 44 & 44 \\
\hline Pali Morado & & & & & & & 25 & 25 \\
\hline Collareja & & & & & & & En proceso & \\
\hline Lagmu & & & & & & & En proceso & \\
\hline Total kg. & & & & 454 & & & 575 & 1.029 \\
\hline
\end{tabular}

Toda la semilla producida en las camas protegidas fue devuelta para la multiplicación en las comunidades de origen en los departamentos de, La Paz involucradas con las instituciones CESA, ACRA,CPA, IABS; en Oruro con la institución UTO, y en Tarija con la Regional ROINPA. Los tubérculos-semillas de tamaño menor a $35 \mathrm{~mm}$ de diámetro fueron multiplicados en camas protegidas, y los de tamaño mayor a $35 \mathrm{~mm}$ de diámetro en parcelas semilleras.

Los cultivares más productivos, tanto in situ como ex situ, fueron Bola Lukí, Majarillo, y Chojlla Lukí entre los cultivares priorizados en 19921993 y entre los cultivares nativos priorizados en la gestión 19941995, estuvieron Milagro, Runa Amarga, Pali Rojo, e Isla. Los elevados rendimientos alcanzados por estos últimos cultivares incentivaron a los agricultores para construir más camas protegidas a 
fin de remultiplicar la semilla producida.

\section{Producción de semilla de calidad básica en sukakollus}

En el departamento de La Paz se coordinó con la institución PROSUKO y Regional PROINPA para acelerar la multiplicación de once de los cultivares nativos para la plantación de plántulas aclimatadas en Sukakollus (Tabla 7). Los Sukakollus son camas a campo abierto para el desarrollo de plantas bordeados por surcos donde circula agua constantemente con el fin de evitar daños por heladas.

Tabla 7. Rendimiento en sukakollus de la comunidad Batallas en la provincia Los Andes del departamento Paz de cultivares de papa nativa priorizados en los años 1992-93 y 199495 (Campaña 1996-1997).

\begin{tabular}{|cc|}
\hline Cultivar & Rend. por Sukakollu (17m $\left.\mathbf{~}^{\mathbf{2}}\right)$ \\
\hline Qetu Luk' i & 32 \\
Bola Luk' i & 42 \\
Puka Ñawi & 27 \\
Pali Negra & 18 \\
Yaku Imilla & 23 \\
Chojlla Luk' i & 34 \\
Runa Amarga & 46 \\
Q'ala Ajanhuiri & 33 \\
\hline
\end{tabular}

Los cultivares más productivos en la campaña 1996-97 fueron los cultivares Runa Amarga, Bola Luk'i, y Chojlla Luk'i, debido a su respuesta bajo estas estructuras llamadas sukakollus, que proporcionaron una humedad apropiada para el desarrollo planta. El ensayo resultó ser una alternativa más para la multiplicación y producción de tubérculos-semillas de alta calidad bajo condiciones de alto riesgo climático especialmente de heladas y sequías.

\section{Multiplicación en parcelas semilleros. Campaña 1996- 1997}

Se identificaron parcelas semilleras in situ en coordinación con una institución involucrada (AGRUCO) y dirigentes de las comunidades previa reunión establecida por ellos mismos en sus comunidades de origen. Así mismo se establecieron parcelas semilleras ex situ en 
Totora Kocha (Cerca a la E.E.Toralapa) y en la provincia Aroma con la institución (CNS). Se plantaron los nueve cultivares de la primera priorización con la semilla de calidad básica obtenida previamente en camas protegidas.

En Tapacarí participaron diferentes agricultores en ocho comunidades obteniéndose los rendimientos más altos con los cultivares Bola Luk'i, Majarillo, Kuchi Sullu y Qetu Luk'i (Tabla 8) así mismo en la provincia Aroma, se obtuvieron los mejores rendimientos con los cultivares Yacu Imilla y Wila Imilla. Lo producido en las parcelas semilleras de Totora Kocha equivale a una semilla Básica II. Se produjo un total de $3,674 \mathrm{Kg}$. de semilla de alta calidad. El área cubierta utilizada total fue aproximadamente de 0.13 ha. La producción promedio lograda (28 t/ha) impactó a los agricultores.

Tabla 8. Rendimiento (Kg.) en parcelas semilleras in situ y ex situ de 15 cultivares de papa nativa priorizados en los años 1992-93 y 1994-95

\begin{tabular}{|c|c|c|c|c|}
\hline Cultivares & $\begin{array}{c}\text { Provincia } \\
\text { Tapacarí } \\
\text { in situ }\end{array}$ & $\begin{array}{c}\text { Provincia } \\
\text { Aroma } \\
\text { ex situ }\end{array}$ & $\begin{array}{l}\text { Totora } \\
\text { Kocha } \\
\text { ex situ }\end{array}$ & $\begin{array}{c}\text { Producción } \\
\text { Total }\end{array}$ \\
\hline \begin{tabular}{|l} 
Bola Luk'i \\
\end{tabular} & 1,386 & & 171 & 1,557 \\
\hline Q'ala Ajanhuiri & 100 & & 85 & 185 \\
\hline Peraza Luk'i & 79 & & 55 & 134 \\
\hline Khuchi Sullu & 260 & & 56 & 316 \\
\hline Qetu Luk'i & 125 & & 184 & 309 \\
\hline Puka Ñawi & & & 49 & 49 \\
\hline Majarillo & 279 & & 256 & 535 \\
\hline Chojlla Luk'i & 80 & & 52 & 132 \\
\hline Morok'o Luk'i & 75 & & 170 & 245 \\
\hline Yacu Imilla & & 67 & & 67 \\
\hline Pali Negra & & 32 & & 32 \\
\hline Sani Negra & & 47 & & 47 \\
\hline Wila Imilla & & 66 & & 66 \\
\hline Total & 2,384 & 212 & 1,078 & 3,674 \\
\hline
\end{tabular}




\section{Comparación in situ de la semilla limpia con otras calidades de semilla}

Para una comparación preliminar se instalaron parcelas compuestas de tres surcos de $30 \mathrm{~m}$ de largo con distanciamiento de $0.65 \mathrm{~m}$ surcos y 0.30 entre plantas.

Se realizaron observaciones en el desarrollo del follaje, apreciándose que la semilla libre de virus (SLV) presentó un mayor desarrollo foliar (altura de planta, cobertura foliar, número de flores, longitud del pedúnculo e intensidad en el color de las hojas) en relación a la semilla proveniente de selección positiva (SSP) y la semilla del agricultor (SA).

La SLV produjo mayor número de tubérculos-semillas en relación a la SSP y a la SA. (Tabla 9). Sin embargo, el rendimiento fue similar en las comunidades de Japo Chaka Cimiento, y Japo Karacochi. En la comunidad Chaka se obtuvo una clara diferencia entre las tres calidades de semilla del cultivar Bola Luk'i donde la SLV rindió de dos a tres veces más en cuanto a número y entre el 57 al $80 \%$ más en peso, con relación a las otras dos calidades.

Es importante mencionar que cuando las parcelas con la SLV encontraban todavía en floración, las parcelas con las otras calidades de semilla ya estaban en senescencia, por lo tanto los ataques de heladas que se presentaron en este período afectaron más la producción de tubérculos de mayor tamaño y peso en las parcelas con SLV que con las otras calidades de semilla por lo tan resultados preliminares obtenidos son alentadores indicando mayor potencial productivo en la semilla libre de virus.

En otras comparaciones realizadas en la comunidad Ahyjadera (3200) de la provincia Loayza en el departamento de La Paz obtenido 19 t/ha con la semilla limpia y 9 t/ha con la semilla del agricultor, del cultivar Pali Rojo, y 18.3 t/ha con la semilla limpia y 8,6 t/ha con la semilla del agricultor del cultivar Sani Negra, en parcelas semilleros. 
Tabla 9. Comparación de rendimientos de semilla libre de virus $(S L V)$, semilla proveniente de selección positiva (SSP) y semilla del agricultor (SA.), en parcelas semilleras in situ, de dos cultivares de papa nativa priorizados en los años 199293. Provincia Tapacarí.

\begin{tabular}{|c|c|c|c|c|c|}
\hline Cultivar & Comunidad & Categoría * & $\begin{array}{l}\text { No de } \\
\text { Tub/pl }\end{array}$ & $\begin{array}{c}\text { Superficie } \\
\mathrm{M}^{2}\end{array}$ & $\begin{array}{c}\text { Rendimiento } \\
\mathrm{kg}\end{array}$ \\
\hline \multirow{4}{*}{ Bola Luk'i } & \multirow{3}{*}{$\begin{array}{c}\text { Japo Chaka } \\
\text { Cimiento }\end{array}$} & SLV & $35-50$ & 112 & 304 \\
\hline & & SSP & $20-35$ & 112 & 320 \\
\hline & & SA & $20-35$ & 112 & 336 \\
\hline & \multirow{3}{*}{ Japo Karacochi } & SLV & 28-36 & 55 & 40 \\
\hline \multirow[t]{3}{*}{ Chojlla Luk'i } & & SSP & $18-25$ & 55 & 43 \\
\hline & & SA & $20-25$ & 55 & 71 \\
\hline & \multirow{3}{*}{ Chaka } & SLV & $19-61$ & 96 & 363 \\
\hline \multirow[t]{2}{*}{ Bola Luk'i } & & SSP & $19-30$ & 96 & 248 \\
\hline & & SA & $20-32$ & 96 & 202 \\
\hline
\end{tabular}

* Semilla libre de virus (SLV); Semilla proveniente de selección positiva (SSP); Semilla del agricultor (SA).

\section{Discusión}

La metodología seguida ha sido altamente satisfactoria para la limpieza de 24 cultivares nativos de Bolivia pertenecientes a $S$. juzepczukii, S. ajanhuiri, S. curtilobum, S. stenotomum, y a $S$. tuberosum ssp. andigena.

La metodología de limpieza, estuvo basada en experiencias previas PROINPA (Aguirre, 1990, Valdivieso, 1994) y en un esquema de limpieza establecido en PROINPA (Villarroel et al., 1998) para la producción de semilla prebásica de los cultivares nativos de $S$. tuberosum ssp. andigena 'Imilla Negra', 'Sani Runa', 'Runa Redonda', 'Gendarme' y 'Wira Malcacho', así como de dos cultivares mejorados Americana y Radosa Rosada, todos ellos de alta importancia comercial en el país.

Aspecto importante en el proceso de limpieza fue el uso de anticuerpos apropiados para la detección mediante DAS-ELISA de variantes andinas de los virus comunes de la papa PVX, PVY y especialmente del PVT-p (PVV) que se presenta como el virus loablemente más importante que afecta y degenera cultivares nativos de papa de altura (Alvarez y Fernández - Northcote, 1996) 
En las pruebas serológicas previas a la termoterapia se detectó que los virus más comúnmente detectados fueron aquellos cuya transmisión por contacto se conoce, como es el caso del PVX y de otros que en trabajos preliminares de PROINPA indican que probablemente también son variantes transmitidas por contacto como el PVY (variante necrótico) y el PTV-p (PVV).

En reportes previos para el Perú (Bertschinger et al., 1990) la baja detección de los virus PVX o PVY en los cultivares nativos Huayro Ccompis, podría deberse al uso de anticuerpos inapropiados para la detección de variantes andinas de dichos virus. En la zona Andina Central del Perú, en el valle del Mantaro, el virus más común en el cultivar nativo Huayro (Solanum chaucha) cultivado a 3,600-4,000 m fue el APLV que se transmite por contacto. No se detectó PVY, PLRV y sólo se detectó un $1 \%$ de PVX. En muestras de cultivares mejorados tomados a menor altura (3,200-3,400 m) los virus más comunes fueron también los que se transmiten por contacto PVS, y APMV. EI PVY y el PLRV fueron detectados en menos de un 4\%. En la zona Andina sur del Perú, en el departamento de Cusco, los virus más comúnmente detectados en el cultivar nativo Ccompis ( $S$. tuberosum ssp. andigena) cultivado en áreas $(3,200 \mathrm{~m})$ donde se alterna con cultivares mejorados, fueron el PVX (43\%) seguido de PVS, PVY y PLRV en menos del $20 \%$ de las muestras.

Los reportes sobre pérdidas en el rendimiento ocasionados por la infección virótica en la zona andina están referidos a cultivares mejorados cultivados por debajo de los 3,500 m donde sólo lo PVY y PLRV transmitidos por áfidos son los que afectan significativamente. Las pérdidas ocasionadas están alrededor del 50\% de la producción potencial (Scheidegger et al., 1995; Iporre, et al. 1996). Pérdidas similares se han observado en el cultivar Sani Imilla en zonas de Bolivia $(3,450 \mathrm{~m})$ donde variantes de estos virus han sido probablemente introducidas (Benitez et al. 1997; Grover et al., 1998) y se presentan poblaciones apropiadas áfidos vectores (Buitrago et al., 1998).

Al presente, en Bolivia varios trabajos han mostrado un incremento entre el 26 al 100\% en la producción, logrado con el empleo de semilla de calidad de los cultivares nativos Waycha y Sani Imilla. Estos son cultivados comúnmente hasta los 3,500 m, en donde es de esperarse un proceso de degeneración por virus transmitidos por contacto y por áfidos (Gonzáles et al., 1994; Iriarte, 1994; Wissar, 
1995; Iporre et al. 1996). En el Perú los resultados obtenidos con el nativo Huayro son similares (Granados y Escalante, 1997).

La mayor parte de los cultivares que se han limpiado en el presente trabajo se cultivan a alturas superiores a los 3,500 m (3,765-4,200 m), donde el proceso de degeneración probablemente está asociado a los virus transmitidos por contacto. El PTV-p (PVV) probablemente juega un rol muy importante en la degeneración de los cultivares nativos cultivados en zonas altiplánicas.

Las pruebas para determinar el potencial productivo y la tasa de degeneración de los cultivares que fueron limpiados en comparación con la semilla degenerada del agricultor y la que en colaboración con instituciones han obtenido por selección positiva, son todavía preliminares, por cuanto los cultivares limpios están en una fase de multiplicación. Sin embargo, los resultados al presente son halagadores aún cuando es más dramático en algunos cultivares que en otros. Así, en el caso del cultivar Bola Luky se viene obteniendo un incremento en los rendimientos del orden del $80 \%$, justificando la preocupación de los agricultores para disponer de semilla "no cansada" (no degenerada) y poder conservar sus cultivares preferidos que reúnen otras características favorables a condiciones y factores limitantes adversos que han permitido su supervivencia. No hay otros reportes en la literatura sobre el efecto benéfico de la limpieza de cultivares nativos altiplánicos.

En el caso de aquellos cultivares nativos en que el potencial productivo y rango de adaptación de la semilla limpia es mayor, es de esperar un incremento sustancial en el área dedicada a su cultivo. En efecto, se viene apreciando un creciente interés por agricultores de zonas diferentes a las del origen del cultivar nativo colectado, en los que el material limpio viene siendo evaluado por PROINPA. Tal es la experiencia previa con el cultivar Imilla Negra (Yana Imilla o Chiar Imilla) (S. tuberosum ssp. andigena), que luego de su rescate y limpieza a solicitud de las comunidades e instituciones interesadas, es un cultivar al presente inserto en el proceso formal de producción de semilla por su alta demanda (Aguirre, 1998).

Al presente, se viene observando una gran demanda para la producción in situ de los cultivares nativos que se han limpiado, lo cual favorecerá su conservación, contribuirá a disminuir la pérdida de biodiversidad y apoyará a una agricultura más sostenible para el bien socioeconómico de una gran masa de pequeños agricultores. 
El uso de las camas protegidas (Aguilar G., 1990; Aguilera J., 1995) permitió el empleo de pequeñas cantidades de material limpio para acelerar su multiplicación a partir de tubérculos-semillas o plántulas in vitro protegiéndolos de condiciones adversas (principalmente heladas y granizadas) habiéndose producido $454 \mathrm{Kg}$. de semilla de alta calidad in situ y $575 \mathrm{Kg}$. ex situ en el término de dos años. Con esta semilla se ha obtenido en parcelas semilleras $2,384 \mathrm{Kg}$. in situ y 1,078 Kg. ex situ, Los sukakollus también se presentan como una buena alternativa para la multiplicación y producción de tubérculos-semillas de alta calidad bajo condiciones de alto riesgo climático. Tanto con las camas protegidas como con los sukakollus los agricultores de bajos recursos económicos pueden empezar a renovar sus cultivares degenerados empezando con pequeñas cantidades de semilla (3-5 Kg.) de alta calidad y valor económico.

Con el presente trabajo se ha logrado el rescate de 24 cultivares nativos de alta importancia local y que estuvieron en peligro de desaparecer por procesos degenerativos, por lo que las comunidades nativas y las instituciones que las apoyan solicitaron su limpieza. Su devolución a las comunidades de origen ha creado una gran expectativa entre los agricultores quienes entre los de mayor edad están apreciando las diferencias morfológicas y potencial productivo en relación a lo que tienen en proceso de degeneración, y entre los más jóvenes conociendo lo que fue común en sus ancestros, pero que dejaron de conocer por el proceso de desaparición de estos cultivares.

\section{Agradecimiento}

Los autores agradecen la asistencia de la Técnico de Laboratorio Tatiana Villafañe (PROINPA), así como al Programa Colaborativo Biodiversidad de Raíces y Tubérculos Andinos, coordinado por el CIP y Financiado por la Cooperación Suiza para el Desarrollo (COSUDE) que posibilitó la ejecución del presente trabajo.

\section{Referencias Bibliográficas}

1. Aguilar, G. 1990. Producción de semilla básica de papa en invernaderos rústicos de bajo costo. SEINPA, Puno, Perú. 
2. Aguilera, J. 1995. Producción de tubérculos-semilla de papa en camas protegidas. Cochabamba, Bolivia, IBTA-PROINPA, Manual Técnico 1.

3. Aguirre, G. 1990. Culture de meristemes et Thermotherapie de varietes boliviennes de Solanum tuberosum L. spp. andigena, Ullucus tuberosus (Lind.) et Oxalis tuberosa (Mol.) en vue de leus assainissement virologique. Tesis M.Sc. Faculté de Sciences Agronomiques. Gembloux, Bélgica.

4. Aguirre, G.; Villarroel, C.L 1998. Contribución a la difusión de cultivares de papa de alta importancia comercial en Bolivia. Página 222 en: Compendio de Exposiciones XVIII Reunión de la Asociación Latinoamericana de la Papa. Febrero 9-13,1998. Cochabamba, Bolivia.

5. Álvarez, V.; Fernández-Northcote, E.N. 1996. Natural occurrence of Perú Tomato Virus potato strain (PTV-p) in Bolivian native potato cultivars. Abstracts of Conference Papers, Posters and demonstrations. 13 th Triennial Conference of the European Association for Potato Research. July 14-19, 1996. Veldhoven, the Netherlands.

6. Badani, A. G.; Iriarte, V.; Villarroel, C. L.; Aguirre, G.; FernándezNorthcote, E. N. 1996. Priorización y limpieza viral de cultivares de papa nativa. En: Memorias de la IV Reunión Nacional de la Papa. Octubre 8-11,1996. Cochabamba, Bolivia.

7. Benítez, E.; Iporre, G.; Alvarez.V.; Fernández-Northcote, E.N. 1997. La enfermedad planta morada en las zonas productoras de papa en Potosí, Bolivia. En: Libro de Resúmenes IX Congreso Latinoamericano de Fitopatología. Octubre 12-17, 1997. Montevideo Uruguay.

8. Bertschinger, L.; Scheidegger.U.; Luther, K.; Pinillos.O.; Hidalgo, A. 1990. La incidencia de virus de papa en cultivares nativos y mejorados en la Sierra Peruana. Revista Latinoamericana de la Papa 3(1):62-79.

9. Bojanic, A. 1995. Sondeo sobre demanda nacional de semilla de papa para el sector formal y su pertinencia para la UPS/SEPA. Informe. Cooperación Técnica Suiza. La Paz, Bolivia.

10. Canaviri, M. 1995. Uso de brotes como alternativa para incrementar las unidades de siembra y la multiplicación de semilla de papa en campo y camas protegidas Tesina Tec. Agr. Universidad Mayor de San Simón. 
11. Fernández-Northcote, E.N., 1992. Importancia de los virus en la producción de la papa. En: Memorias II Reunión Nacional de la Papa. Noviembre 1992.Cochabamba, Bolivia.

12. Gonzales, S.; Devaux, A.; Fernández-Northcote, E.N.; Alvarez, V., 1994. Evaluación agronómica de la semilla certificada bajo condiciones de producción de agricultores. En: Compendio de exposiciones III Reunión Nacional de la Papa. Septiembre 2023 1994. Cochabamba, Bolivia.

13. Granados, C.; Escalante, B. 1997. Eficiencia de la erradicación de virus en el rendimiento de variedades nativas de papa (Solanum tuberosum L.) a nivel de campo en Cajamarca. En: Libro de Resúmenes. IX Congreso Internacional de Cultivos Andinos. Abril 22-25 1997. Cusco, Perú. p. 71.

14. Horton, D. 1992. La Papa: Producción, Comercialización y Programas. CIP, Lima y Hemisferio Sur, Montevideo.

15. Iporre, G.; Alvarez, V.; Fernández-Northcote, E.N. 1996 Determinación de la tasa de degeneración de cultivares y clones promisorios en las pampas de Lequesana, Potosí. En: Compendio de Exposiciones, IV Reunión Nacional de la Papa Octubre 08-11.1996. Cochabamba, Bolivia.

16. Iporre, G.; Alvarez, V.; Fernández-Northcote, E.N. 1998. Como reconocer y evitar la planta morada en el cultivo de la papa. Serie Ficha Técnica 9/98, Fitopatología, PROINPA.

17. Iriarte, V. 1994 Evaluación de la degeneración del tubérculo semilla de papa del cultivar Waycha en la provincia Arani. En: Compendio de Exposiciones III Reunión Nacional de la Papa. Septiembre 20-23, 1994. Cochabamba, Bolivia.

18. Iriarte, V.; Aguirre, G.; Villarroel, C. L.; Badani, A. G.; FernándezNorthcote, E. N. 1998. Recuperación y Producción de cultivares nativos de papa en Bolivia. En: Compendio de Exposiciones Reunión de la Asociación Latinoamericana de la Papa. Febr 13, 1998. Cochabamba, Bolivia.

19. Iriarte, V.; Badani, A. G.; Villarroel, C. L.; Aguirre, G.; FernándezNorthcote, E. N. 1996. Producción de semilla de calidad básica de cultivares nativos de papa libres de virus en camas protegidas En: Memorias de la IV Reunión Nacional de la Papa. Octubre 11,1996. Cochabamba, Bolivia. 
20. Valdivieso, R. 1994. Obtención de cinco cultivares de papa (Solanum tuberosum L.) libres de patógenos mediante cultivo de meristemas y termoterapia in vitro. Tesis Ing. Agr. Universidad Mayor de San Simón.

22. Villarroel, C.L.; Aguirre, G.; Fernández-Northcote, E.N. 1998. Proceso de limpieza viral establecido en PROINPA. En: Compendio de Exposiciones XVIII Reunión de la Asociación Latinoamericana de la Papa. Febrero 9-13, 1998. Cochabamba, Bolivia.

23. Scheidegger, U.; Bertschinger, L.; Luther, K.; Pinillos O.; Muñoz, J.; Hidalgo, A. 1995 . El efecto de diferentes virus sobre el rendimiento potencial de la papa en la sierra central del Perú, Revista Latinoamericana de la papa. 7/8(1):25-35.

24. Wissar, R. 1995. Producción de tubérculos-semilla de papa con pequeños agricultores en la región de Potosí- Bolivia. Revista Latinoamericana de la Papa. 7/8(1):1-15.

25. Zeballos, H. 1997. Aspectos económicos de la producción de papa en Bolivia. COSUDE-CIP, Lima, Perú. 